\title{
The Experimental Analysis of Verbal Behavior
}

\author{
A. Charles Catania and Eliot Shimoff \\ University of Maryland Baltimore County
}

The verbal behavior literature, in the pages of this journal and elsewhere, includes both data-based research on verbal behavior and talk about verbal behavior. Acknowledging that we have ourselves occasionally contributed to the imbalance, we nevertheless believe that there should be more of the former and less of the latter. For example, we once submitted a chapter to a book about verbally governed behavior, and when the book appeared we were surprised to discover that among the 10 contributions in it ours was the only one to present original data (Catania, Shimoff, \& Matthews, 1989). We therefore offer here a few suggestions about some possibilities for enhancing the experimental database for the analysis of verbal behavior. Depending on the available time and resources, we may some day get to one or another of these topics ourselves. But we are not likely to start on any of them in the near future, and we surely will never be able to cover all of them, so we offer these suggestions in the hope that some others will take them up. The worst that would happen if more than one investigator got to work on the same topic is that each would become more experienced in gathering data on verbal behavior and that some findings would be strengthened (or questioned) by replication. The most welcome commentary we could get on our suggestions would be the presentation of data sets from one or more of these research lines.

Verbally governed and contingency-shaped behavior. Verbally governed behavior is a

For reprints, write either author at the Department of Psychology, University of Maryland Baltimore County, 1000 Hilltop Circle, Baltimore, Maryland 21250 (E-mail: catania@umbc.edu or shimoff@umbc.edu). higher order class in which control of behavior by verbal antecedents is maintained by social contingencies and perhaps by other contingencies having to do with consistencies of behavior across different contexts (as in reading and writing). It includes not only instruction following but also other cases in which self- or other-generated verbal behavior changes the likelihood of subsequent verbal and nonverbal behavior (we speak of verbally governed rather than rulegoverned behavior here because the former term is more general and avoids controversies over what constitutes a rule: Catania, 1998, in press; Shimoff \& Catania, in press). When behavior is verbally governed (controlled by the contingencies that maintain the higher order class), it may be insensitive to other nonverbal contingencies, in the sense that changes in those nonverbal contingencies will be less likely to produce changes in behavior than they would have been in the absence of verbal governance (e.g., a well-trained soldier will be likely to follow orders and move forward in a combat situation, even though natural contingencies favor moving in the opposite direction). That is the main reason for distinguishing between verbally governed and contingency-shaped behavior.

We would like to know more about the developmental origins of verbally governed behavior. We know that it can be demonstrated with 4- or 5-year-olds and that the effectiveness of instructions and a range of other properties of verbal behavior develop at and around that age (e.g., Bentall \& Lowe, 1987; Catania, Lowe, \& Horne, 1990; Horne \& Lowe, 1996). Cognitive developmental psychologists have created a substantial literature on the order and time course with 
which various semantic and syntactic competencies develop in children. From their work we can learn about the development of some of the structural properties of verbal behavior, but we should be learning more about the development of its functions and the variables that drive that development.

The relations between verbal and nonverbal behavior may also be relevant to other developmental phenomena. In Piagetian conservation, for example, children go through a stage in which they identify tall narrow containers as containing more than shorter wider containers with the same volume. Such phenomena involve both the circumstances under which children learn the vocabularies of more and equal and less and those in which they learn to choose among the contents of different containers. We have been unable to find studies in the developmental literature that explicitly compare the acquisition of that verbal behavior with changes in the nonverbal selection of the contents of comparable containers. Similar strategies could be used in studying the conjunction fallacy (e.g., Tversky \& Kahneman, 1983) and other cases of probability estimation in which verbal judgments are inconsistent with nonverbal contingencies. Such studies all involve the analysis of the parallel development of verbal and nonverbal stimulus control over verbal and nonverbal responses, and are among many possible ways to explore the development of relations between verbal and nonverbal behavior while also providing data that may attract an audience of researchers who approach these issues from other perspectives.

The shaping of verbal behavior. The everyday vocabulary of verbal behavior does not lend itself well to our talking about the variables that control our own verbal behavior, and for that reason our verbal behavior itself may be more likely to be free of verbal governance than other nonverbal varieties of human behavior. In other words, verbal behavior may typically be contingency shaped rather than verbally governed. If that were not so, the shaping of verbal behavior would probably be as problematic as the shaping of nonverbal human behavior when the latter is verbally governed and therefore relatively insensitive to nonverbal contingencies. The shaping of verbal behavior is well established in our experimental literature (e.g., Catania, Matthews, \& Shimoff, 1982; Greenspoon, 1955; Truax, 1966), but we have only scratched the surface of its possible applications. For example, are some behavior pathologies, such as compulsions, problems of verbal governance (cf. Chadwick, Lowe, Horne, \& Higson, 1994)? If verbal behavior is predominantly contingency shaped, it should be possible to use it to study effects of schedule contingencies on human behavior that have been obscured by verbal governance in human nonverbal tasks (such as button pressing).

One problem with shaping the content of verbal behavior is that it may be necessary to arrange different contingencies for maintaining the behavior than for shaping particular instances. In shaping the content of conversation, the experimenter must keep the conversation going while also engaged in shaping. We have occasionally entertained the possibility of recruiting students into a purported study of automatic writing. They would be asked to read "Has Gertrude Stein a Secret?" by B. F. Skinner (1934) and then they would be told to try to produce automatic writing at a computer keyboard. Our instructions would say that we were developing new statistical tests for the properties of automatic writing versus other kinds of writing and that the computer would give them feedback whenever their behavior satisfied our tests. But if that feedback was instead contingent on, say, plural nouns according to a fixed-interval schedule or on first-person pronouns according to a variable-ratio schedule (or maybe both concurrently), would those verbal units be sensitive to those contingencies in ways comparable to the nonverbal responses of nonverbal organisms? The collection of verbal data by computer would be straightforward in such a procedure, and the problems of automated scheduling and data analysis that would have made such research unthinkable some years ago are now likely to yield to advances that are now routinely incorporated into word processing and other computer programming. For those interested in tapping the strength of verbal response classes, analyzing typed computer 
input could also be applied to other verbal behavior that is not highly determined by current stimuli, as in Thematic Apperception Test materials, Rorschach inkblots, and Skinner's (1957) verbal summator.

The vocabulary of feelings and other private events. In his classic paper on psychological terms, Skinner (1945) addressed the dependence of the vocabulary of private events on public stimuli accessible to the verbal community. Philip N. Hineline once told us about data he had collected that were relevant to Skinner's points. He had asked students to describe their feelings in past emotional situations, and found that the descriptions were much less likely to report private events than they were to report public events such as details of the situations. We have since occasionally replicated his general finding. For example, one of us entered a classroom in a course on verbal behavior on a day when an exam was not scheduled and began handing out exam booklets. When the students were told to start, they read the following: "This is not an exam. Now describe your feelings when you saw me start to give out the exam booklets." The majority of the responses consisted of descriptions of the situation and of private verbal behavior ("I didn't think there was supposed to be an exam today" or "I thought you made a mistake, and I didn't feel prepared for an exam"). Those that did seem to qualify as reports of feelings were typically global ("I panicked") or metaphorical rather than literal ("My heart fell to the floor"). The subsequent class discussion of these responses nicely demonstrated the limitations of the language of feelings, but the procedure also illustrates that it is possible to collect verbal data that are relevant to these issues.

There are other ways to get at the acquisition of the language of private events. For example, consider the vocabulary of remembering, forgetting, and never having known (e.g., Wellman, 1990). Children learn to report whether they have forgotten something or never knew it in the first place. They are not ordinarily taught explicitly; they learn through natural contingencies, in the context of being asked questions and answering them. But it is not difficult to construct artificial contingencies that will be similarly effective. Imagine a child who one day is taught names for a set of objects. The next day the child is asked to name those objects and a few new ones. For some objects the child's naming is successful, and for others it is not. Appropriate differential reinforcement can now be arranged for three different verbal responses: given successful naming, "I remembered"; given an original object and unsuccessful naming, "I forgot"; and given a new object and necessarily unsuccessful naming, "I don't know." With this start, the vocabulary can easily be extended to other tasks.

As programs for teaching these reports of private events, these procedures make the public correlates explicit. It would be misleading to seek the controlling variables of such reports inside the child, because the reports are established on the basis of public events available to the verbal community. By demonstrating how a verbal community can shape such vocabularies, which sometimes also appear as components of cognitive accounts of behavior, we move toward an experimental analysis not only of the child's verbal behavior but also of the verbal behavior of those who study it. The vocabulary of mind is presumably shaped by natural contingencies, but such contingencies can shape vocabularies of dragons and unicorns as well as those of lions and giraffes. The mental vocabulary is not a guide for the experimental analysis of verbal behavior, but it should not be neglected as a potential object of that analysis.

Extending the analysis of verbal behavior. So much for our suggestions. Obviously we have not exhausted the many possibilities for studying verbal behavior experimentally. For example, we have not discussed metaphor and other extensions of verbal behavior or applications of the analysis of verbal behavior to education or the simulation of verbal functions in nonverbal organisms. We would also not presume to discourage the analysis of verbal data from nonexperimental sources, as in the search for natural contingencies in the acquisition of verbal behavior (e.g., Moerk, 1992) or in the interpretation of literature or poetry or other instances of preserved verbal behavior (the 
precedent for which is provided in Skinner, 1957). Data-based research on verbal behavior has increased since Skinner's seminal work, but it remains a small literature in comparison with what is available in developmental psycholinguistics and related disciplines outside of the experimental analysis of behavior. Hints at what it might be possible to do are accessible in many experimental journals concerned with development and language. For example, studies in the Journal of Child Language often describe progressions in the normative development of verbal behavior in children, leaving open the kinds of questions that behavior analysts should be prepared to address, such as the nature of contingencies that operate to create such verbal behavior in an individual child. In the face of the marvelous complexity of verbal behavior, it is clear that we have hardly begun to tap its vast potential. The contingencies that favor talk rather than data collection are obvious (Skinner, 1959). Enough talk. We need to get back to the laboratory.

\section{REFERENCES}

Bentall, R. P., \& Lowe, C. F. (1987). The role of verbal behavior in human learning: III. Instructional effects in children. Journal of the Experimental Analysis of Behavior, 47, 177-190.

Catania, A. C. (1998). Learning (4th ed.). Upper Saddle River, NJ: Prentice Hall.

Catania, A. C. (in press). The taxonomy of verbal behavior. In K. A. Lattal \& M. Perone (Eds.), Handbook of human operant behavioral research methods. New York: Plenum.
Catania, A. C., Lowe, C. F., \& Horne, P. (1990). Nonverbal behavior correlated with the shaped verbal behavior of children. The Analysis of Verbal Behavior, 8, 43-55.

Catania, A. C., Matthews, B. A., \& Shimoff, E. (1982). Instructed versus shaped human verbal behavior: Interactions with nonverbal responding. Journal of the Experimental Analysis of Behavior, 38, 233-248.

Catania, A. C., Shimoff, E., \& Matthews, B. A. (1989). An experimental analysis of rule-governed behavior. In S. C. Hayes (Ed.), Rule-governed behavior: Cognition, contingencies, and instructional control (pp. 119-150). New York: Plenum.

Chadwick, P. D. J., Lowe, C. F., Horne, P. J., \& Higson, P. J. (1994). Modifying delusions: The role of empirical testing. Behavior Therapy, 25, 35-49.

Greenspoon, J. (1955). The reinforcing effect of two spoken sounds on the frequency of two responses. American Journal of Psychology, 68, 409-416.

Horne, P. J., \& Lowe, C. F. (1996). On the origins of naming and other symbolic behavior. Journal of the Experimental Analysis of Behavior, 65, 185-241.

Moerk, E. L. (1992). First language: Taught and learned. Baltimore: Paul H. Brookes.

Shimoff, E., \& Catania, A. C. (in press). The verbal governance of behavior. In K. A. Lattal \& M. Perone (Eds.), Handbook of human operant behavioral research methods. New York: Plenum.

Skinner, B. F. (1934, January). Has Gertrude Stein a secret? Atlantic Monthly, 153, 50-57.

Skinner, B. F. (1945). The operational analysis of psychological terms. Psychological Review, 52, 270-277.

Skinner, B. F. (1957). Verbal behavior. New York: Appleton-Century-Crofts.

Skinner, B. F. (1959). The flight from the laboratory. In B. F. Skinner, Cumulative record (pp. 242-257). New York: Appleton-Century-Crofts.

Truax, C. B. (1966). Reinforcement and nonreinforcement in Rogerian therapy. Journal of Abnormal Psychology, 71, 1-9.

Tversky, A., \& Kahneman, D. (1983). Extensional versus intuitive reasoning: The conjunction fallacy in probability judgment. Psychological Review, 90, 293-315.

Wellman, H. M. (1990). The child's theory of mind. Cambridge, MA: MIT Press. 